\title{
Un método simplificado para evaluar el riesgo sísmico y priorizar la atención de los bienes culturales inmuebles: el caso de Chile
}

A Simplified Method to Assess Seismic Risk and Prioritize the Care of Immovable Cultural Heritage: Chile as a Case Study

\section{Daniela Andrea Díaz Fuentes}

Università degli Studi della Basilicata (UB), Italia

daniela.diazfue@gmail.com

\section{Resumen}

Hoy en día existe una gran necesidad de generar planes integrales de gestión del riesgo para la conservación y protección del patrimonio cultural inmueble en zonas altamente propensas a fenómenos naturales asociados con catástrofes, tales como el Circum Pacífico o Anillo de Fuego del Pacífico. Esta INVESTIGACIÓN presenta, inicialmente, un procedimiento de evaluación de riesgos mediante la aplicación de tres herramientas: la priorización de la asistencia con base en el valor cultural, la evaluación y mapeo de amenazas y la ponderación de la vulnerabilidad sísmica; posteriomente, se plantea el proceso de perfeccionamiento y aplicación metodológica en su aplicación a seis casos de estudio: antiguas iglesias de mampostería de piedra y adobe, en Chile.

\section{Palabras clave}

evaluación de riesgos; vulnerabilidad; amenazas; valor cultural; arquitectura religiosa

\section{Abstract}

Nowadays there is a great need for the generation of integral risk management plans to preserve and protect immovable cultural heritage in areas extremely prone to natural disasters, such as the Circum-Pacific Belt or Pacific Ring of Fire. This RESEARCH initially presents a risk evaluation procedure based on the implementation of three tools: cultural-value prioritization, evaluation/mapping of threats, and seismic vulnerability assessment; subsequently, it shows the application of this method to six case studies: old church paths of stone masonry and adobe in Chile.

\section{Key words}

risk assessment; vulnerability; threats; cultural value; religious architecture 


\section{Introducción}

E n zonas geográficas con una alta frecuencia de fenómenos naturales asociados con catástrofes se han desarrollado principios y manuales para la gestión de riesgos en el ámbito de la conservación de los bienes culturales inmuebles, la mayoría de éstos, elaborados por la Organización de las Naciones Unidas para la Educación, la Ciencia y la Cultura (UNESCO), el Consejo Internacional de Monumentos y Sitios (ICOMOS), el Centro Internacional de Estudios para la Conservación y la Restauración de los Bienes Culturales (ICCROM) y el Getty Conservation Institute (GCI). La primera guía que propuso lineamientos de prevención ante la amenaza sísmica y el riesgo de incendio fue Between Two Earthquakes: Cultural Property in Seismic Zones (Feilden 1987), que enfatizó la importancia del mantenimiento regular, así como de la ejecución de medidas de conservación preventiva y de la microzonificación sísmica. Otros ejemplos de manuales son, en primer lugar, el Risk Preparedness: A Management Manual for World Cultural Heritage (Stovel 1998), que planteó la necesidad de una planificación integral del bien patrimonial y el paisaje asociado en tres etapas: la prevención, la respuesta y la recuperación, incluidos la documentación, el inventario y la inspección de los bienes para identificar cuáles requieren un cuidado especial en caso de emergencia y medidas de conservación preventiva (Stovel 1998:9), y, en segundo, el Managing Disaster Risks for World Heritage (UNESCO 2010), que, por una parte, complementó el manual de Stovel (1998), al incorporar, además de las amenazas esporádicas causadas por fenómenos meteorológicos, hidrológicos o geológicos, aquellas que responden a procesos continuos acumulativos, como la erosión, el turismo masivo o la contaminación atmosférica, y, por la otra, respaldó las técnicas y los materiales tradicionales para el mantenimiento y la consolidación de los bienes inmuebles combinados con técnicas modernas (UNESCO 2010:8-40).

Asimismo, se han puesto en práctica programas de prevención y manejo de desastres tales como la Carta del Rischio (ICR 1992), en Italia, y el Programa de prevención de desastres en materia de patrimonio cultural (INAH 2002, 2009, 2013), en México. Sin embargo, en países latinoamericanos emplazados en sitios de alto riesgo, como el Anillo de Fuego, o Circum Pacifico, ${ }^{1}$ no se han

\footnotetext{
1 El Circum Pacifico, o Anillo de Fuego del Pacífico, se ubica en las costas del océano Pacífico y se caracteriza por concentrar algunas de las zonas de subducción más importantes del mundo, lo que ocasiona una intensa actividad sísmica y volcánica en las zonas que abarca. Incluye a Chile, Argentina, Bolivia, Perú, Ecuador, Colombia, Panamá, Costa Rica, Nicaragua, El Salvador, Honduras, Guatemala, México, Estados Unidos de América, Canadá, donde dobla, a la altura de las islas Aleutianas, y baja por las costas e islas de Rusia, Japón, Taiwán, Filipinas, Indonesia, Malasia, Timor Oriental, Brunéi, Singapur, Papúa Nueva Guinea, Islas Salomón, Tonga, Samoa, Tuvalu y Nueva Zelanda (véase usGs 2016).
}

elaborado planes integrales de gestión del riesgo para la conservación del patrimonio cultural inmueble.

En este contexto, desde la perspectiva de la conservación preventiva del patrimonio cultural inmueble, el libro Diseño de herramientas de evaluación del riesgo para la conservación del patrimonio cultural inmueble. Aplicación en dos casos de estudio del norte andino chileno (Díaz 2016) propuso una metodología conformada por tres herramientas:

La herramienta 1 se diseñó para priorizar la atención de los bienes inmuebles ante una calamidad derivada de un fenómeno natural mediante la evaluación de la rareza o singularidad de sus valores culturales, lo que los convierte en bienes escasos a escala local, nacional o internacional.

Las herramientas restantes abordaron la evaluación del riesgo, al establecer, con base en el documento desarroIlado por Guglielmo De Angelis (1972) para el ICCROM, una relación entre las amenazas y vulnerabilidades, y las causas de deterioro de los edificios históricos. Estas últimas pueden dividirse en dos grupos: las intrínsecas, ligadas al origen y naturaleza del edificio, que constituyen su vulnerabilidad constructiva, y las extrínsecas, que tienen que ver con las condiciones de su ubicación y corresponden a las amenazas (Díaz 2016:23).

Los resultados de la aplicación de las herramientas 2 y 3 en cinco iglesias del norte andino chileno emplazadas en la Quebrada de Tarapacá se mostraron en un ensayo previo (Díaz 2015), por lo que el objeto de esta INVESTIGACIÓN se centra en la evaluación de las tres herramientas en las cinco iglesias mencionadas en dos vertientes: por un lado, cuantificando los resultados, y por el otro, evaluando un sexto caso, que representa un contrapunto, de la misma tipología constructiva y en el mismo país: esto es, una iglesia, también chilena, pero ahora ubicada en un contexto territorial diverso. Lo anterior tiene la intención de evaluar la efectividad de este procedimiento, particularmente, en su aplicabilidad regional en América Latina.

\section{Descripción de la metodología}

Se ha señalado que la metodología propuesta por Díaz (2016) cuenta con tres herramientas: a continuación se describen sucintamente.

Herramienta 1: priorización de la atención del patrimonio cultural inmueble en función del valor patrimonial

Como lo menciona su nombre, el objetivo de la herramienta 1 incluida en la metodología desarrollada por Díaz (2016:27-67) es priorizar la atención de los bienes culturales inmuebles en un contexto de catástrofe o emergencia asociada con un fenómeno natural, ejercicio que se elabora con base en su valor cultural. Al res- 
pecto, cabe señalar que muchos países cuentan con un marco legal y procedimientos específicos para proteger su patrimonio cultural, como los instrumentos de las declaratorias o el catálogo en los que se enuncian, identifican y explicitan los atributos y valores culturales del bien inmueble en cuestión, por ejemplo: la Declaración de Valor Universal Excepcional adoptada para la inscripción de los bienes culturales en la Lista del Patrimonio Mundial (UNESCO 2008:42); los decretos de declaratoria como monumento nacional en el marco de la ley núm. 17.288 de Chile (ME 2016:15) o la ficha de inventario de bienes culturales inmuebles colombiana (MC 2005: anexo 79). Esta identificación —que depende del valor asignado no sólo por la sociedad involucrada directamente con el bien sino, además, por la comunidad científica y el Estado- es producto de un consenso entre las partes el cual es relevante al momento de decidir qué conservar primero en un contexto de emergencia posterior a un desastre asociado con un fenómeno natural, tal como lo señala Josep Ballart (1997:120), "parece fuera de dudas que sólo la sociedad en su conjunto por medio de sus portavoces sociales y políticos, y mediante la acción reguladora del Estado es la que puede asumir la responsabilidad de valorizar en mayor o menor grado este tipo de recursos públicos".

Estos documentos le dan base a la herramienta 1 para analizar el bien inmueble en función de un listado de valores culturales, una tipología que se estableció, a su vez, en clasificaciones que han considerado el valor más allá de las cualidades propias del bien cultural — también como el producto de la relación entre el bien y la comunidad (Díaz 2016) - y fueron propuestas por teóricos como Aloïs Riegl (1903), Françoise Choay (2007) y Josep Ballart (1997), así como por documentos de normativa internacional, como The Burra Charter: The Australia ICOMOS Charter for Places of Cultural Significance (ICOMOS 2013), el Documento de Nara, Japón, Sobre la autenticidad de los valores patrimoniales (ICOMOS 1994) y el Assessing the Values of Cultural Heritage (De la Torre 2002), publicado por el GCI.

A pesar de la subjetividad y contingencia de los valores patrimoniales, cuando se planifica la conservación de los bienes culturales inmuebles éstos deben clasificarse en tipologías, aunque sean provisionales y no sean aplicables en todos los sitios o situaciones. Los autores y documentos arriba mencionados coinciden en la definición de tipologías de valores, como los históricos, artísticos o estéticos y sociales, y algunos proponen los de antigüedad, los simbólico-significativos, los científicos, los educativos, los de uso y los económicos (Díaz 2016:59-60).

Basándose en las tipologías de valores señalados, y si se considera que algunas de ellas se traslapan en sus significados, la metodología articula una matriz que prevé la valoración del bien cultural dependiendo de las siguientes variables:

- Valor de antigüedad, entendido como la huella del tiempo o la antigüedad del emplazamiento del bien inmueble.

- Valor histórico, que evalúa el bien como testimonio de un suceso, personaje, etapa o actividad histórica.

- Valor simbólico-significativo, entendido como el aprecio en que se tienen los objetos del pasado como vehículos de una forma de relación entre quienes los produjeron o utilizaron y sus actuales receptores.

- Valor estético, que considera aspectos de percepción sensorial según criterios como la forma, la escala, el color, la textura, el material, los olores, los sonidos, entre otros, vinculados con el sitio y su utilización.

- Valor científico, entendido como potencial de investigación de un lugar y que depende de la importancia de la información que exista, de su rareza, su calidad y su capacidad representativa:

- Valor de uso, entendido como valor instrumental, dimensión utilitaria o fin práctico del inmueble.

Adicionalmente, para priorizar la atención, a cada tipología valorativa del listado se le otorga una calificación alta, media y baja, con una ponderación de 3,2 y 1, respectivamente. Ello se relativiza en tres escalas de análisis: local, nacional e internacional (Díaz 2016:59). En la primera se estiman los valores culturales de acuerdo con la autenticidad e integridad del bien, analizando la presencia, ausencia y grado de alteración de los elementos en que, según The Burra Charter for Places of Cultural Significance (ICOMOS 2013) y el Documento de Nara, Japón, Sobre la autenticidad de los valores patrimoniales (ICOMOS 1994), se corporiza cada valor cultural, y que corresponden a: los materiales, técnicas, fábrica, concepto, forma, emplazamiento, entorno, significados, uso y función, tradición, espíritu y sentimiento, asociaciones, registros, sitios y objetos relacionados. Por su parte, lo que se valora en la escala nacional (Díaz 2016:60) es el grado de escasez del bien cultural, comparándolo con otros de la misma tipología funcional (iglesias, viviendas, escuelas, infraestructura, etc.) con base en su representatividad en el inventario de bienes protegidos por ley en cada país. Por último, en la escala internacional (Díaz 2016:62) se pondera con un puntaje 3 si el sitio está inscrito en la Lista del Patrimonio Mundial (UNESCO 2008), con un puntaje 2 si se encuentra en la lista tentativa para su inscripción, o bien, con un puntaje 1 para los demás inmuebles; por ello se asigna una calificación constante en todos los valores (Figura 1).

Herramienta 2: descripción y jerarquización de amenazas del patrimonio cultural inmueble

La segunda herramienta que Díaz (2016) desarrolla, la cual tiene como finalidad describir y jerarquizar las amenazas, se diseñó a partir del estudio de documentos en el ámbito de la planificación territorial y la conservación 


\begin{tabular}{|c|c|c|c|c|c|c|}
\hline & & & & & deración & \\
\hline $\begin{array}{l}\mathbf{N} \\
\mathbf{C u} \\
\text { Ubi } \\
\text { Geo }\end{array}$ & $\begin{array}{l}\text { mbre del bien } \\
\text { tural inmueble } \\
\text { ación } \\
\text { eferenciación }\end{array}$ & $\begin{array}{l}\text { Fotografía representativa } \\
\text { del bien cultural inmueble }\end{array}$ & $\begin{array}{c}\text { Integridad } \\
\text { Autenticidad } \\
\text { 3: } 71-100 \% \\
2: 41-70 \% \\
1: 0-40 \%\end{array}$ & $\begin{array}{c}\text { Escasez } \\
\text { a nivel } \\
\text { nacional } \\
\text { Alta: } 3 \\
\text { Media: } 2 \\
\text { Baja: } 1\end{array}$ & $\begin{array}{c}\text { Excepcionalidad } \\
\text { (único o raro) } \\
\text { Sitio de patrimonio } \\
\text { Mundial: } 3 \\
\text { Lista tentativa para SPM: } 2 \\
\text { Otros: } 1\end{array}$ & $\begin{array}{l}\text { Resultado } \\
\text { (Promedio) }\end{array}$ \\
\hline & $\begin{array}{l}\text { Antigüedad } \\
\text { (Huella del tiempo) }\end{array}$ & $\begin{array}{l}\text { Huella del tiempo en mate- } \\
\text { riales y fábrica }\end{array}$ & & & & \\
\hline$\frac{\mathrm{g}}{\frac{0}{\sigma}}$ & $\begin{array}{l}\text { Histórico } \\
\text { (Asociado a un hecho históri- } \\
\text { co, autor o comitente) }\end{array}$ & $\begin{array}{l}\text { Fábrica, uso, asociaciones, } \\
\text { registros, sitios y objetos } \\
\text { relacionados }\end{array}$ & & & & \\
\hline 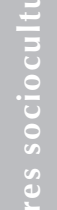 & $\begin{array}{l}\text { Simbólico-significativo } \\
\text { (Conmemorativo, voluntad de } \\
\text { recordar, significación en el } \\
\text { contexto urbano, relación con } \\
\text { el entorno) }\end{array}$ & $\begin{array}{l}\text { Técnicas, entorno, signifi- } \\
\text { cados, uso y función, tradi- } \\
\text { ción, espíritu y sentimiento }\end{array}$ & & & & \\
\hline$\frac{\overline{0}}{\frac{15}{5}}$ & $\begin{array}{l}\text { Estético } \\
\text { (Representatividad, inserción } \\
\text { en una determinada corriente } \\
\text { estilística, belleza y relación } \\
\text { con el arte) }\end{array}$ & $\begin{array}{l}\text { Concepto, forma, materia- } \\
\text { les, fábrica, emplazamiento } \\
\text { y sentimiento }\end{array}$ & & & & \\
\hline 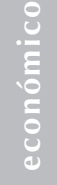 & $\begin{array}{l}\text { Científico } \\
\text { (Fábrica, materiales y técnicas } \\
\text { utilizadas, grado de innova- } \\
\text { ción) }\end{array}$ & $\begin{array}{l}\text { Fábrica, materiales y téc- } \\
\text { nicas }\end{array}$ & & & & \\
\hline$\frac{\frac{\pi}{2}}{\frac{0}{3}}$ & $\begin{array}{l}\text { Uso o valor económico } \\
\text { (Función, asociaciones y sitios } \\
\text { relacionados; valor de cambio) }\end{array}$ & $\begin{array}{l}\text { Asociaciones, sitios relacio- } \\
\text { nados, uso y función }\end{array}$ & & & & \\
\hline & & Resultado & & & & \\
\hline
\end{tabular}

FIGURA 1. Tabla de priorización de la atención del patrimonio cultural inmueble en función del valor patrimonial; herramienta 1 (Fuente: Díaz 2016:67).

del patrimonio, en los que se destacan los atlas, o mapas, de amenazas a escala de macrozonificación, es decir, en el ámbito nacional, más que en el local, realizados por el Centro Nacional de Prevención de Desastres (Cenapred 2001, 2006), en México, y la ya citada Carta del Rischio (ICR 1992), en Italia. Otros ejemplos de análisis de riesgos en Sudamérica revisados fueron, en Chile, la Guía de análisis de riesgos naturales para el ordenamiento territorial (Subdere 2011) y los estudios para el manejo de riesgos en el sitio UNESCO de Valparaíso (OGPMV 2008), en el cual se concede especial importancia al de incendio, y, en Perú, la microzonificación sísmica del centro de Lima (Degg y Chester 2005), que tuvo el objeto de definir zonas seguras para la planificación urbana (Díaz 2016:87). Para organizar y jerarquizar las amenazas se utilizaron dos documentos: el Manual de gestión de riesgos de colecciones (ICCROM y UNESCO 2009), que propuso una forma de organizar las amenazas en relación con su pro- babilidad de ocurrencia, y Managing Disaster Risks for World Heritage (UNESCO 2010), que planteó clasificar las amenazas según la gravedad de sus consecuencias en el patrimonio cultural inmueble (Díaz 2016:114).

Esta herramienta se aplica con fundamento en un análisis determinístico y global de las amenazas que eventualmente afectarían al bien cultural en cuestión, definiendo el peor escenario posible con base en la información histórica sobre la magnitud e intensidad de los fenómenos. Posteriormente las amenazas se priorizan de acuerdo con la gravedad de los daños que podrían causar en el edificio histórico. En la Figura 2 se muestra la clasificación de las empleadas en la metodología que implican tres grupos principales: a) amenazas naturales de acción ocasional; b) amenazas de naturaleza física, y c) amenaza antrópica y química.

Dado que al emplear la segunda herramienta en esta investigación se busca evaluar el riesgo sísmico, no se 


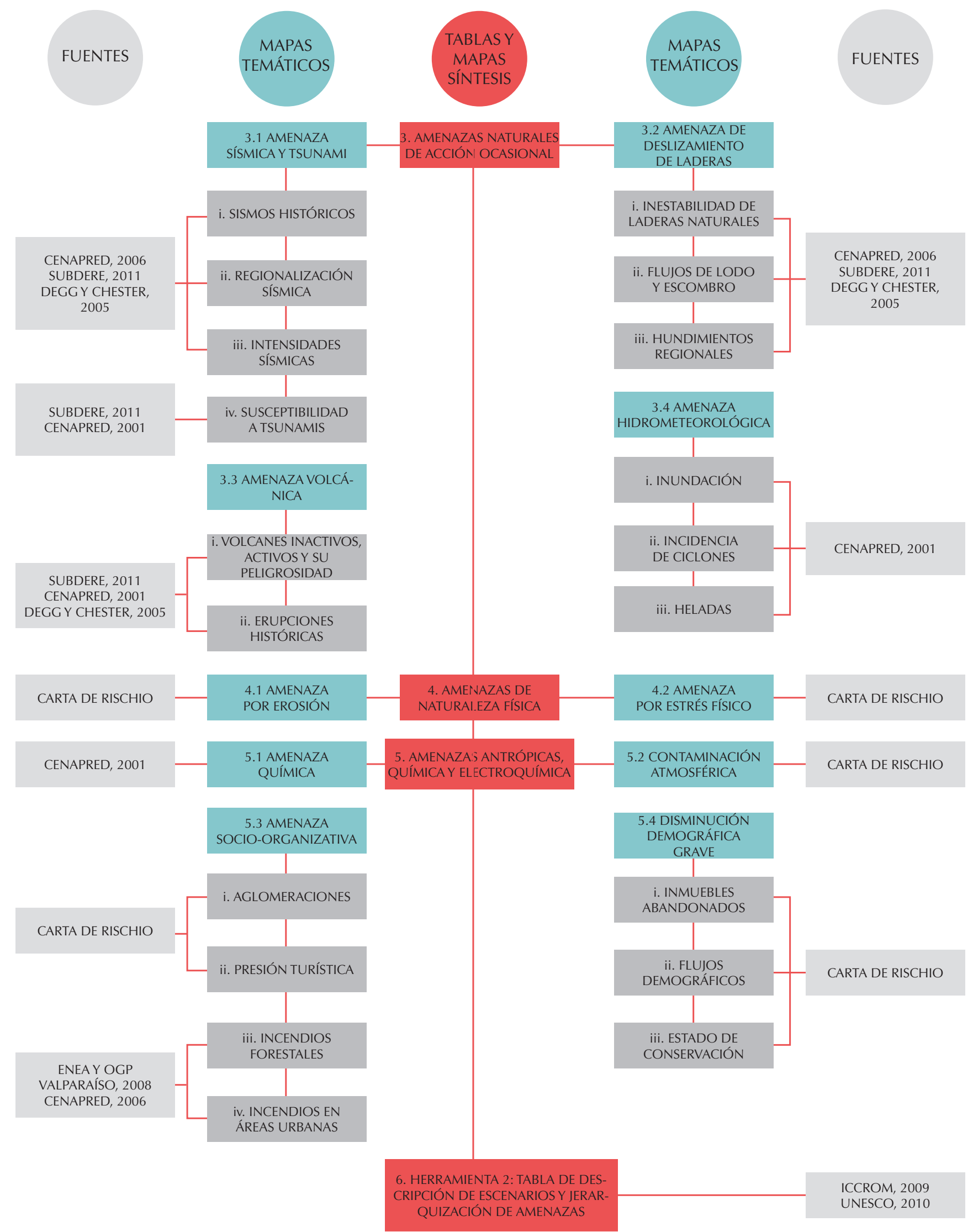

FIGURA 2. Esquema de los parámetros para realizar la descripción y jerarquización de amenazas del patrimonio cultural inmueble; herramienta 2 (Fuente: Díaz 2016:71). 
toman en cuenta las amenazas volcánicas, hidrometeorológicas y químicas (riesgo de incendio por industrias cercanas); sí, en cambio, los deslizamientos de laderas, por razón de que es una consecuencia probable de un terremoto de intensidad alta. Asimismo, se analizan las amenazas que corresponden a procesos continuos, como la erosión y el estrés físico; contaminación atmosférica; socioorganizativa, y disminución demográfica grave, con la consecuente falta de mantenimiento, debido a que la principal consecuencia de estas amenazas es el deterioro material de los edificios patrimoniales.

El primer paso para evaluar la amenaza sísmica incluye la investigación de los terremotos históricos, su intensidad, la aceleración máxima del suelo y la distancia desde el epicentro, incluido también, mediante el estudio de las zonas de inundación, el peligro de tsunami (Díaz 2016:75-81). Por su parte, para la amenaza de deslizamientos de laderas se considera: la topografía y la geometría de las pendientes; la distribución de la estratificación geológica y las propiedades mecánicas del suelo; las precipitaciones ordinarias y extraordinarias; la hidrología superficial y subterránea, y la identificación de las intervenciones antropogénicas que puedan haber causado cambios en el sistema de presión de agua subterránea o en la geometría de la pendiente, o bien, sobrecarga o la deforestación sin una evaluación técnica (Díaz 2016:82-89). Por medio del análisis de estos parámetros se establece el peor escenario con base en la inestabilidad de los taludes naturales; la presencia probable de flujos de lodo y escombros, y los hundimientos regionales o locales.

Dado que las amenazas de procesos naturales continuos se producen al menos una vez al año y están relacionadas con la posición geográfica, el clima y el contexto social (Díaz 2016:107-112), para evaluar la amenaza de erosión se tienen en cuenta la precipitación media y máxima, la distancia a la costa, la humedad relativa y la dirección y velocidad de los vientos dominantes. Adicionalmente, para ponderar la amenaza de estrés físico se evalúan, además de las precipitaciones, el daño probable en los materiales por una fuerte oscilación térmica, y la confluencia de la lluvia y temperaturas inferiores a $0{ }^{\circ} \mathrm{C}$, que podrían provocar el congelamiento de las partículas de agua y la consecuente desintegración o agrietamiento de los materiales (Díaz 2016:100-101). Por otra parte, para la contaminación atmosférica se calculan: las zonas con congestión vehicular; la ubicación de los aeropuertos y puertos; las autopistas y la circulación diaria de automóviles, con el fin de sopesar el probable ennegrecimiento de los materiales o su disolución por la lluvia ácida. En la valoración de amenaza socio-organizacional, que se refiere al riesgo de vandalismo o guerras, o a los daños que pueden provocar las aglomeraciones de personas a causa del turismo en los bienes culturales inmuebles, se analiza la presión turística, que, justamente, por la concentración de personas, tiene como consecuencia la sobrecarga o condensación de vapor de agua en el edificio, y la probabilidad de incendio, mediante el estudio de materiales combustibles cercanos, las condiciones climáticas, la continuidad de las construcciones y la presencia de cables eléctricos defectuosos (Díaz 2016:107-111). Finalmente, la probable falta de mantenimiento de los edificios históricos se analiza estudiando la grave disminución demográfica, que se relaciona con el estado de abandono de los edificios históricos reflejado en un deterioro progresivo, situación que se genera, por ejemplo, en poblados rurales afectados por procesos de migración de sus habitantes o en centros históricos que pierden su carácter residencial en favor de la actividad comercial o administrativa, quedando a cargo de arrendatarios que no suelen hacerse cargo de su mantenimiento (Díaz 2016:111). Esta amenaza se analiza identificando la ubicación de los edificios abandonados y su estado de conservación.

En el procedimiento, tras evaluar cada una de estas amenazas de forma grupal, se establece el peor escenario posible, el cual se clasifica en función de la gravedad del daño que podría provocar en el bien inmueble en cuestión. El resultado se clasifica en tres categorías: sin daños, leve o gradual, o catastrófico. En la investigación actualmente en proceso se ha propuesto ponderar estos parámetros según la Figura 3.

\begin{tabular}{|c|c|c|c|c|}
\hline \multirow{2}{*}{\multicolumn{2}{|c|}{ Parámetros }} & \multicolumn{3}{|c|}{ Severidad del daño } \\
\hline & & \multirow{2}{*}{$\begin{array}{c}\begin{array}{c}\text { Sin } \\
\text { daño/Sin } \\
\text { amenaza }\end{array} \\
0 \\
0\end{array}$} & \multirow{2}{*}{$\begin{array}{c}\begin{array}{c}\text { Leve o } \\
\text { gradual }\end{array} \\
0.20\end{array}$} & \multirow{2}{*}{$\begin{array}{c}\text { Catastrófica } \\
0.40\end{array}$} \\
\hline \multirow{2}{*}{$\begin{array}{l}\text { Eventos } \\
\text { esporádicos } \\
\text { (EE) }\end{array}$} & $\begin{array}{l}\text { Intensidad } \\
\text { máxima } \\
\text { Mercalli }\end{array}$ & & & \\
\hline & $\begin{array}{l}\text { Deslizamiento } \\
\text { de laderas o } \\
\text { fractura }\end{array}$ & 0 & 0.15 & 0.25 \\
\hline \multirow{5}{*}{$\begin{array}{l}\text { Procesos } \\
\text { continuos } \\
\text { (PC) }\end{array}$} & Erosión & 0 & 0.05 & 0.10 \\
\hline & Estrés físico & 0 & 0.05 & 0.10 \\
\hline & $\begin{array}{l}\text { Contaminación } \\
\text { atmosférica }\end{array}$ & 0 & 0.01 & 0.05 \\
\hline & $\begin{array}{l}\text { Socio - } \\
\text { organizativa }\end{array}$ & 0 & 0.01 & 0.05 \\
\hline & $\begin{array}{l}\text { Disminución } \\
\text { demográfica } \\
\text { grave }\end{array}$ & 0 & 0.01 & 0.05 \\
\hline
\end{tabular}

FIGURA 3. Puntaje de los parámetros para definir el índice de amenaza (Tabla: Daniela Díaz Fuentes, 2016).

Herramienta 3: ficha de evaluación y cuantificación de la vulnerabilidad sísmica en los bienes culturales inmuebles

La tercera herramienta propuesta en Díaz (2016) evalúa la vulnerabilidad sísmica mediante parámetros que se definieron de acuerdo con la ficha desarrollada por la Direzione Generale delle Politiche Territoriale e Ambientali 


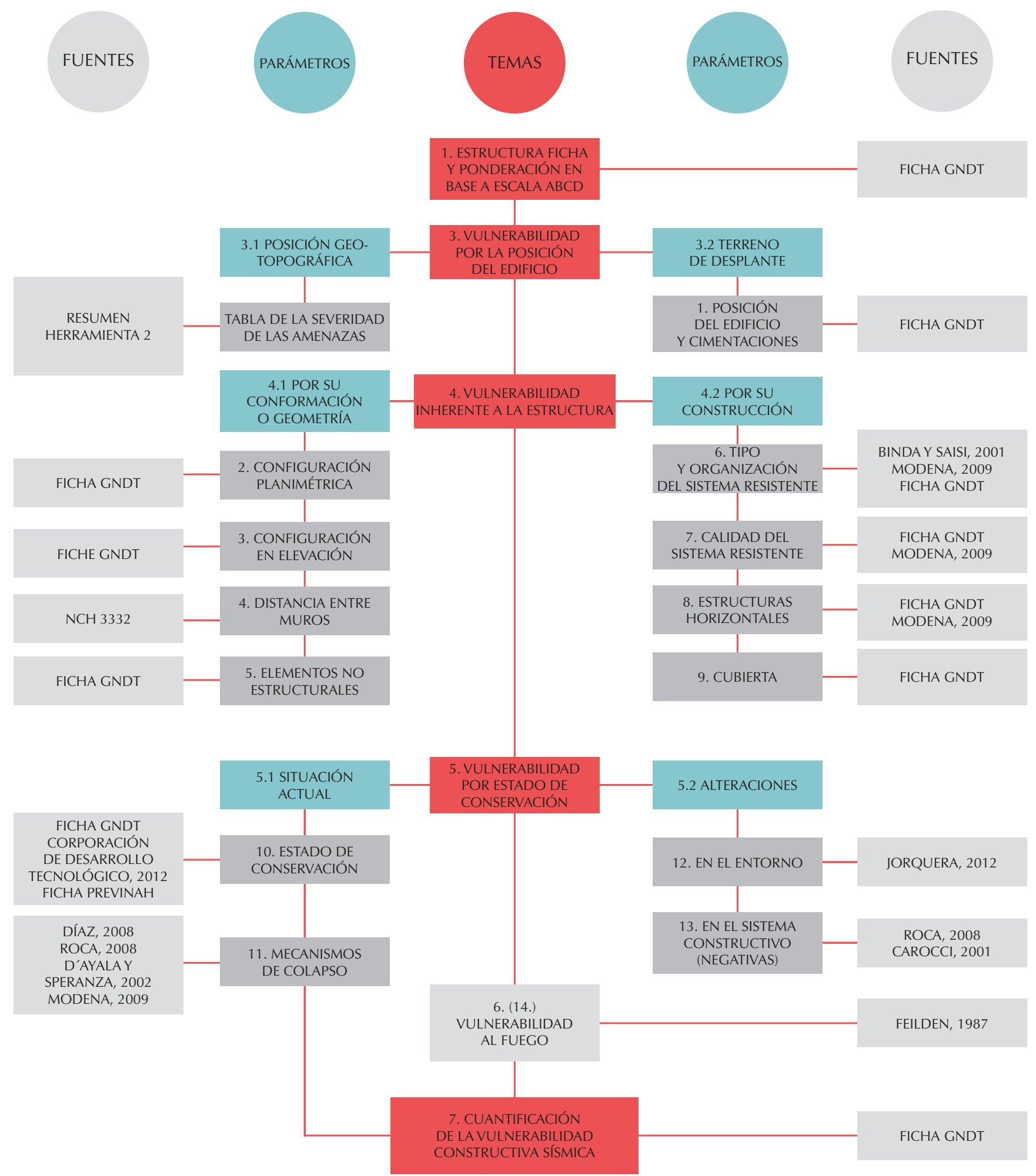

FIGURA 4. Esquema de los parámetros para realizar la evaluación y cuantificación de la vulnerabilidad constructiva sísmica en los bienes culturales inmuebles; herramienta 3 (Fuente: Díaz 2016:127).

de Italia (DGPTA 2003), pero también, para incluir la tipología constructiva de adobe, se utilizó la Norma núm. 3332 de Chile (INN 2013) y el documento Evaluación de daños y soluciones para construcciones en tierra cruda. Manual de terreno (CDT 2012), para considerar la vulne- rabilidad al fuego, consecuencia usual de los terremotos, el ya referido Between Two Earthquakes: Cultural Property in Seismic Zones (Feilden 1987), publicado por el GTI, y, para incorporar datos relacionados con el estado de conservación, los lineamientos desarrollados por el Ins- 
tituto Nacional de Antropología e Historia (INAH 2010) de México.

Asimismo se tuvieron presentes varios artículos recientes sobre temas relacionados con el comportamiento sísmico de las construcciones de mampostería, como: la estabilidad de las secciones de muros por la presencia de trabas transversales (Binda y Saisi 2001); la consolidación con materiales similares a los originales en términos de forma, dimensiones, espesor y resistencia para lograr el comportamiento monolítico (cfr. Carocci 2001; Modena 2009), y dicho comportamiento a través de los mecanismos de colapso (cfr. D'Ayala y Speranza 2002; Roca 2008; Díaz 2008). Además, se incluyeron algunos indicadores sociales que indirectamente podrían aumentar la vulnerabilidad constructiva del bien cultural inmueble, como la accesibilidad, el aislamiento, la relación con el contexto geográfico y la comunidad, entre otros, propuestos por Natalia Jorquera (2012).

Los parámetros de la tercera herramienta se dividen en tres tipos de vulnerabilidad: por la posición del edificio; la inherente a la estructura, y por el estado de conservación (Figura 4).

El rubro sobre la vulnerabilidad por la posición del edificio estima:

- Las amenazas relacionadas con la posición geotopográfica y

- el tipo de suelo, la pendiente (si la hay) y el tipo de cimentaciones (Díaz 2016:128-134).

Adicionalmente, la temática de la vulnerabilidad inherente a la estructura considera:

- La configuración planimétrica o geometría, es decir, la asimetría del edificio, que aumenta su vulnerabilidad ante un terremoto;

- la configuración en elevación, que, a su vez, valora la distribución y continuidad de los elementos resistentes a lo largo de la altura;

- la distancia entre muros, que calibra, entre otros, la esbeltez de los muros, los desplomes, la ubicación de los vanos, la distancia entre muros transversales para evitar el volteo;

- los elementos no estructurales, esto es, los accesorios, los elementos verticales y los voladizos que podrían caer en un terremoto;

- la organización y calidad del sistema inherente, es decir, el sistema constructivo, los materiales, la traba entre los muros ortogonales y la conexión entre los muros y entrepisos mediante estructuras ejecutadas con materiales compatibles, y

- las estructuras horizontales y cubierta en relación con la capacidad de deformación en el plano, la compatibilidad de los materiales, los empujes producidos en los muros y el tipo de conexión con los mismos (Díaz 2016:134-171).
Por último, el rubro sobre la vulnerabilidad por el estado de conservación evalúa:

- Los deterioros visibles en el edificio;

- las alteraciones en el sistema constructivo;

- las alteraciones negativas en el entorno que han incrementado su fragilidad y

- la vulnerabilidad al fuego, tomando en cuenta la presencia de adornos o muebles inflamables, la falta de compartimentación y divisiones internas, las actividades peligrosas realizadas en el interior del inmueble, etcétera (Díaz 2016:172-188).

En la cuantificación de la vulnerabilidad sísmica, cada uno de los parámetros tiene un peso acorde con su relevancia en la vulnerabilidad total del edificio, la cual se pondera en una escala A, B, C y D, donde A indica una muy baja y $D$, una muy alta. Los valores y el peso de cada parámetro se basaron en la ficha y tabla para la cuantificación de la vulnerabilidad desarrollada por la ya mencionada Direzione Generale delle Politiche Territoriale e Ambientali (DGPTA 2003). No obstante que en la herramienta planteada por Díaz (2016:117-192) los parámetros de la ficha se modificaron y adaptaron con el fin de hacerlos apropiados para evaluar el patrimonio cultural inmueble, se mantuvieron las proporciones propuestas por la ficha italiana (Figura 5).

\begin{tabular}{|c|c|c|c|c|c|c|}
\hline \multirow{2}{*}{\multicolumn{2}{|c|}{ Parámetros }} & \multicolumn{4}{|c|}{ Clase } & \multirow{3}{*}{$\begin{array}{l}\text { Peso } \\
0.75\end{array}$} \\
\hline & & \multirow{2}{*}{ A } & \multirow{2}{*}{$\begin{array}{c}\text { B } \\
1.35\end{array}$} & \multirow{2}{*}{$\frac{C}{6.73}$} & \multirow{2}{*}{$\frac{\text { D }}{12.12}$} & \\
\hline 1 & $\begin{array}{l}\text { Posición del edificio y } \\
\text { cimentaciones }\end{array}$ & & & & & \\
\hline 2 & $\begin{array}{l}\text { Configuración } \\
\text { planimétrica }\end{array}$ & 0 & 1.35 & 6.73 & 12.12 & 0.5 \\
\hline 3 & $\begin{array}{l}\text { Configuración en } \\
\text { elevación }\end{array}$ & 0 & 1.35 & 6.73 & 12.12 & 1.0 \\
\hline 4 & Distancia entre muros & 0 & 1.35 & 6.73 & 12.12 & 0.25 \\
\hline 5 & $\begin{array}{l}\text { Elementos no } \\
\text { estructurales }\end{array}$ & 0 & 0 & 6.73 & 12.12 & 0.25 \\
\hline 6 & $\begin{array}{l}\text { Tipo y organización del } \\
\text { sistema resistente }\end{array}$ & 0 & 1.35 & 6.73 & 12.12 & 1.5 \\
\hline 7 & $\begin{array}{l}\text { Calidad del sistema } \\
\text { resistente }\end{array}$ & 0 & 1.35 & 6.73 & 12.12 & 0.25 \\
\hline 8 & Estructuras horizontales & 0 & 1.35 & 6.73 & 12.12 & 1.0 \\
\hline 9 & Cubierta & 0 & 1.35 & 6.73 & 12.12 & 1.0 \\
\hline 10 & Estado de conservación & 0 & 1.35 & 6.73 & 12.12 & 1.0 \\
\hline 11 & $\begin{array}{l}\text { Alteraciones en el } \\
\text { entorno }\end{array}$ & 0 & 1.35 & 6.73 & 12.12 & 0.25 \\
\hline 12 & $\begin{array}{l}\text { Alteraciones en el } \\
\text { sistema constructivo }\end{array}$ & 0 & 1.35 & 6.73 & 12.12 & 0.25 \\
\hline 13 & Vulnerabilidad al fuego & 0 & 1.35 & 6.73 & 12.12 & 0.25 \\
\hline
\end{tabular}

FIGURA 5. Puntaje y peso de los parámetros para definir el índice de vulnerabilidad (Tabla: Daniela Díaz Fuentes, 2016). 
Así, el índice de vulnerabilidad se define mediante la ecuación 1 (Figura 6):

$$
V=\sum_{i=1}^{n} v_{i} p_{i}
$$

FIGURA 6. Ecuación 1 para definir la vulnerabilidad (Fuentes: Laterza et al. 2016a, 2016b; Guida et al. 2016).

Puesto que en la literatura internacional se considera que el riesgo es "la combinación de la probabilidad de que ocurra un evento y sus consecuencias negativas" (UNISDR 2009:29), posteriormente, el índice de vulnerabilidad se multiplica por el índice de amenaza para calcular el riesgo sísmico mediante la ecuación 2 (Figura 7).

$$
\mathrm{R}=\mathrm{V} *(\mathrm{~A}+\mathrm{l})
$$

FIGURA 7. Ecuación 2, el índice de vulnerabilidad se multiplica por el índice de amenaza para calcular el riesgo sísmico (Fuentes: Laterza et al. 2016a, 2016b; Guida et al. 2016).

Aplicación del procedimiento en seis iglesias del norte andino de Chile

Durante esta INVESTIGACIÓN, la metodología se aplicó en la iglesia de Chiu Chiu, construida en 1611 (Wikiwand 2016) en el Oasis de Chiu Chiu, y, en la Quebrada de Tarapacá, en las iglesias de Limaxiña, Laonzana, Sibaya y Usmagama, erigidas a mediados del sigo XVII (ME 2009; Dibam 2016b), así como en la de Huaviña, del siglo XVIII (Dibam 2016a), todas ubicadas en el norte andino de Chile (Figura 8), construidas en adobe y mampostería de piedra asentada en lodo, con techumbre de par y nudillo de madera local y cubierta de paja brava o torta de lodo; arquitectónicamente, presentan una nave única, con una o dos torres del campanario adosadas o exentas, y un atrio delimitado por un muro perimetral (Díaz et al. 2012:153) (Figura 9).

\section{Aplicación de la herramienta 1}

En Chile la declaración de un bien inmueble como monumento nacional conlleva una justificación sobre su relevancia ante el Consejo de Monumentos Nacionales (CMN), organismo colegiado que decide si aquél amerita el reconocimiento en alguna de las categorías de pro-

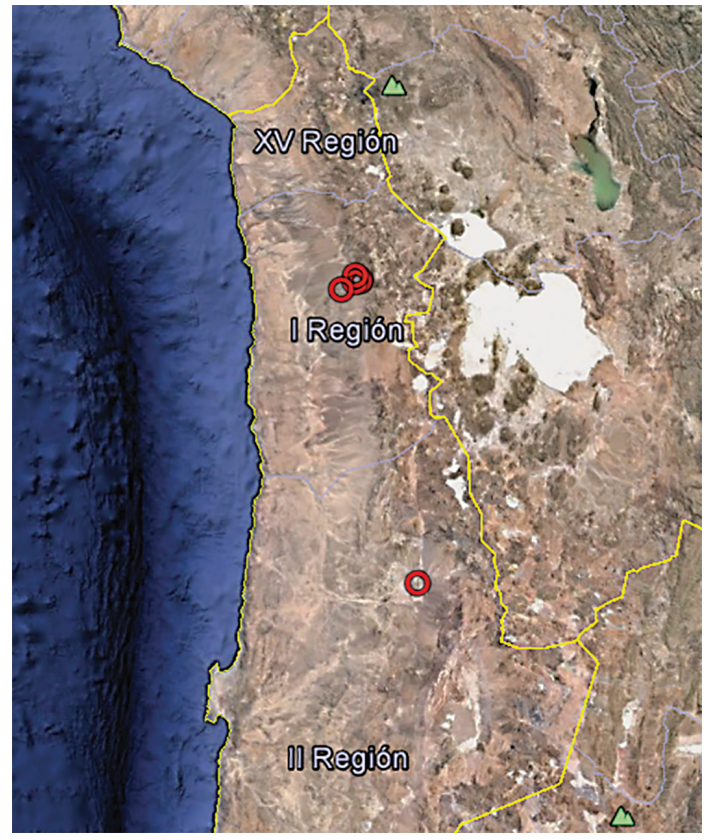

FIGURA 8. Ubicación geográfica de las iglesias en la Quebrada de Tarapacá, I Región de Chile, y en el oasis de Chiu Chiu, II Región de Chile (Fuente: Google Earth; Geoportal del CMN, Chile, 2016).
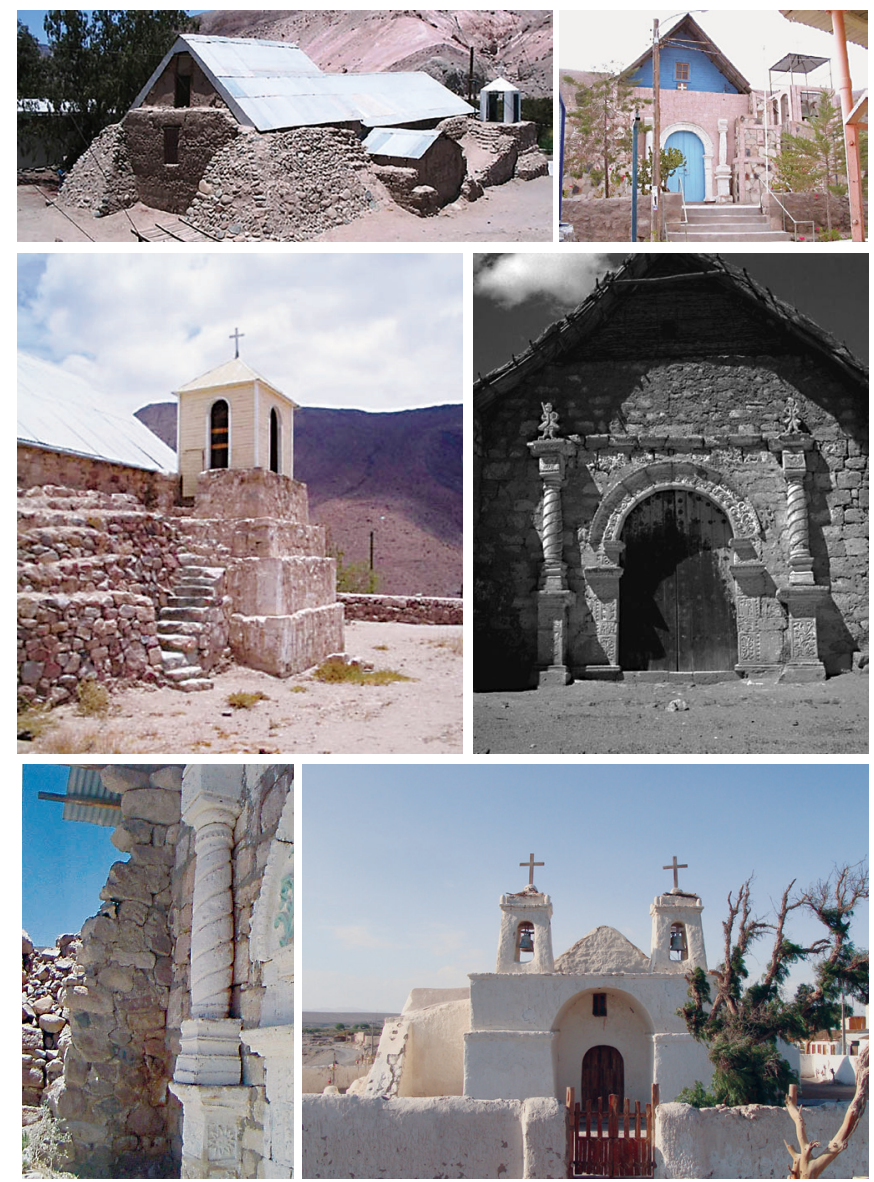

FIGURA 9. Fotografías previas al terremoto de 2005: 9a. Iglesia de Laonzana; 9b. Iglesia de Sibaya; 9c. Iglesia de Limacsiña; 9d. Iglesia de Huaviña; 9e. Iglesia de Usmagama; 9f. Iglesia de Chiu Chiu (Fuente: Dibam 2016; cortesía Consejo de Monumentos Nacionales, Chile). 
tección de acuerdo con la Ley 17.288 de Monumentos Nacionales y Normas Relacionadas (ME 2016:107-114). Una vez aprobada dicha declaratoria, el Ministerio de Educación (ME) emite un decreto de declaratoria, ${ }^{2}$ que explicita las características del bien y los valores culturales que lo hicieron meritorio del reconocimiento nacional (ME 2016:15). En la actualidad, en Chile éste es el único documento que refleja un consenso respecto de los valores culturales de un bien inmueble y, por lo tanto, se empleó en este estudio como la base para la aplicación de la herramienta 1 . No obstante, debe mencionarse que aunque estos decretos se han emitido desde 1926, ${ }^{3}$ sólo desde la década de los noventa describen los valores culturales de los monumentos (Dibam 2016c). Por esta razón, la información de los decretos de las iglesias de Chiu Chiu, Usmagama y Huaviña, emitidos en la década de los cincuenta, debió complementarse con reseñas históricas disponibles en el sitio web del CMN (Dibam 2016a, 2016b).

Ahora bien, respecto de la primera escala de análisis, en este caso, local, ya que las seis iglesias corresponden a la misma tipología histórico-arquitectónica denominada iglesias del altiplano, emplazada en la cordillera de los Andes, no existen grandes variaciones en la ponderación de los valores culturales. En cuanto al valor de antigüedad, el emplazamiento de estos templos generalmente está asociado con sitios sagrados o cementerios preexistentes (Díaz et al. 2012:152), no obstante, la más antigua, y primera de su categoría tipológica, fue Chiu Chiu, de 1611, mientras que las demás se construyeron a mediados del siglo XVII y en el siglo XVIII (ME 2009; Dibam 2016a, 2016b). Estas variantes temporales implicaron diferencias en su ponderación. Respecto de los valores histórico, simbólico-significativo y científico, a todas las iglesias se les asignó igual puntaje. Las diferencias se hicieron notar tanto en el valor estético, en función del menor o mayor grado de alteración que afecta la legibilidad de la arquitectura andina, como en el valor de uso, ya

\footnotetext{
2 "El Decreto Supremo num. 19 del Ministerio Secretaría General de la Presidencia delega en los ministros de Estado de Chile la facultad de suscribir, bajo la fórmula "por orden del presidente de la República", los decretos supremos relativos a diversas materias. En el caso del Ministerio de Educación (ME), una de esas materias es la "declaración de Monumentos Nacionales de conformidad con la Ley núm. 17.288" (art. 1, numeral X, núm. 4). Publicado en el Diario Oficial el 10 de febrero de 2001" (ME 2016:15).

3 "La Ley núm. 17.288 de Monumentos Nacionales y Normas Relacionadas data de 1970 y sus antecedentes directos se remontan al año 1925, con el Decreto Supremo núm. 3.500, que encarga a una comisión la redacción de un proyecto de ley sobre monumentos nacionales; y el posterior Decreto Ley 651, del mismo periodo, que en definitiva crea el Consejo de Monumentos Nacionales y establece las disposiciones para nuestros monumentos que rigieron los siguientes 45 años" (ME 2016:8). Según la Nómina de Monumentos Nacionales, el primer Decreto Supremo que declaró un monumento nacional se dictó el 23 de marzo de 1926 (cfr. Dibam 2016c).
}

que la comunidad indígena atacameña usa la iglesia de Chiu Chiu constantemente durante el año y, en particular, en las festividades religiosas, mientras que las cinco iglesias de la Quebrada de Tarapacá se utilizan prácticamente sólo en las festividades, debido a la migración de las comunidades indígenas aimaras (Díaz et al. 2012:153).

Para la ponderación a escala nacional se partió de la base de la existencia de 214 iglesias declaradas monumento histórico en Chile, de las cuales 45 (21\%) corresponden a esta tipología (Dibam 2016c), y luego se evaluó la escasez de cada uno de los valores en comparación con las demás iglesias tuteladas. Por último, el puntaje a escala internacional fue el mismo en los seis casos, debido a que esta tipología de iglesias se encuentra en la Lista Tentativa de Sitios de Patrimonio Mundial postulados por Chile ante el Centro de Patrimonio Mundial de la UNESCO (CMN 2004:13-15).

Considerando la ponderación de prioridad: alta (3), media (2) y baja (1), los resultados de la aplicación de la herramienta 1 en los casos de estudio - específicamente, el promedio de las tres escalas (local, nacional e internacional) - en cada valor cultural se muestran en la Figura 10.

\begin{tabular}{|l|c|c|c|c|c|c|}
\hline \multirow{2}{*}{ Valores } & \multicolumn{7}{|c|}{ Iglesias } \\
\cline { 2 - 7 } & $\begin{array}{l}\text { Chiu } \\
\text { Chiu }\end{array}$ & Limacsiña & Laonzana & Huaviña & Sibaya & Usmagama \\
\hline Antigüedad & 2.66 & 1.66 & 1.33 & 1.66 & 1.66 & 1.66 \\
\hline Histórico & 2.33 & 2.33 & 2.33 & 2.33 & 2.33 & 2.33 \\
\hline $\begin{array}{l}\text { Simbólico- } \\
\text { significativo }\end{array}$ & 2.66 & 2.66 & 2.66 & 2.66 & 2.66 & 2.66 \\
\hline Estético & 2.66 & 2.00 & 1.66 & 2.00 & 1.66 & 2.33 \\
\hline Científico & 2.33 & 2.00 & 2.00 & 2.00 & 2.00 & 2.00 \\
\hline $\begin{array}{l}\text { Uso o valor } \\
\text { económico }\end{array}$ & 2.33 & 1.66 & 1.66 & 1.66 & 1.66 & 1.66 \\
\hline $\begin{array}{l}\text { Índice } \\
\text { de valor } \\
\text { cultural }\end{array}$ & $\mathbf{2 . 4 9}$ & $\mathbf{2 . 0 5}$ & $\mathbf{1 . 9 4}$ & $\mathbf{2 . 0 5}$ & $\mathbf{1 . 9 9}$ & $\mathbf{2 . 1 1}$ \\
\hline
\end{tabular}

FIGURA 10. Tabla con los resultados de la priorización por valor cultural (Tabla: Daniela Díaz Fuentes, 2016).

Aplicación de las herramientas 2 y 3

En un ensayo publicado previamente (Díaz 2015) se presentaron los resultados de la aplicación de las herramientas 2 y 3 en las cinco iglesias de los pueblos de: Laonzana, Sibaya, Limaxiña, Huaviña y Usmagama, todas ellas situadas dentro de la Quebrada de Tarapacá. Dado que, tras el terremoto de junio de 2005, los inmuebles experimentaron daños estructurales graves y colapsos en más de 60\% de su estructura (Díaz et al. 2012:82-89), la metodologia se aplicó retroactivamente, esto es, considerando la condición previa al terremoto registrada en los expedientes de las iglesias y archivada en el Centro de Documentación del Consejo de Monumentos Nacio- 
nales (CDCMN). ${ }^{4}$ Así, la efectividad del procedimiento se ponderó al comparar sus resultados con los efectos reales posterremoto. Para el presente estudio se siguió la misma lógica de evaluación, con la salvedad de que se agregó el analisis de la iglesia de san Francisco de Chiu Chiu, emplazada en el Oasis de Chiu Chiu, la cual presenta dos variables distintas: por un lado, con el terremoto el inmueble resultó con daños estructurales reparables (Díaz et al. 2012:90), y por el otro, se encuentra en un contexto cultural muy rico, ya que, como se ha señalado, es el centro religioso de la comunidad indígena acatameña.

Un aspecto digno de mencionar es que la amenaza sísmica en la Quebrada de Tarapacá (Figura 11) es indicativa de consecuencias catastróficas para las personas y las construcciones, debido a que en la Región de Tarapacá han ocurrido 11 terremotos sobre la magnitud 7 en 145 años, y la máxima alcanzó 8.5 e intensidad Mercalli de X, en 1877 (CSN 2016). Asimismo, es grave la amenaza de deslizamientos de laderas, ya que la presencia de precipitaciones en el invierno altiplánico podría cambiar las propiedades mecánicas de suelos en pendientes sobre $10 \%$ y relativamente inestables, constituidos por depósitos de remoción en masa, abanicos aluviales y deslizamientos gravitacionales (Sernageomin 2003). El daño aún podría potenciarse por las temperaturas extremas, que pueden fluctuar entre $0{ }^{\circ} \mathrm{C}$ y $30^{\circ} \mathrm{C}$ en un mismo día (DGA 2016), pudiendo producir fracturas de la roca por termoclastismo, ${ }^{5}$ situación que, en caso de precipitaciones o terremoto, aumentaría la inestabilidad (Díaz 2016:216).

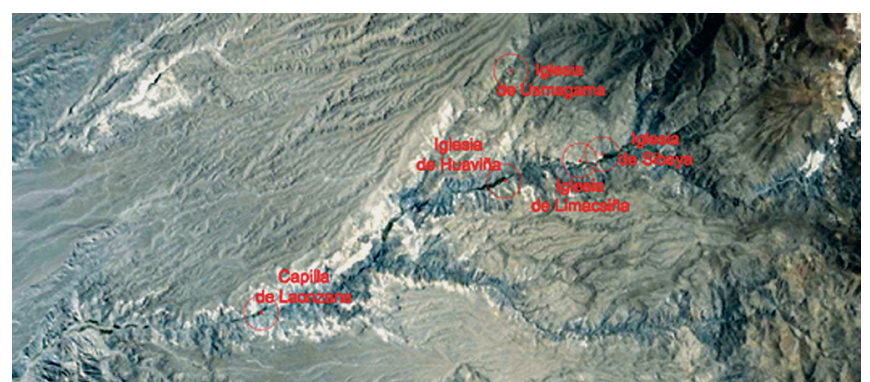

FIGURA 11. Ubicación geográfica de las iglesias en la Quebrada de Tarapacá (Fuente: Google Earth y Geoportal del CMN, Chile, 2015).

${ }^{4}$ Luego de la declaratoria de un monumento nacional en el marco de la Ley 17.288 de Monumentos Nacionales, la documentación derivada de las solicitudes de intervención da origen a un archivo documental ordenado por expedientes físicos, que se encuentran a disposición de los usuarios en el Centro de Documentación del Consejo de Monumentos Nacionales (Cedoc-CMN) (ME 2016:124). En este caso se revisaron los expedientes de las seis iglesias declaradas monumento histórico que corresponden a los casos de estudio (cfr. CDCMN 2009a, 2009b, 2009c, 1953a, 1953b, 1951).

${ }^{5}$ El termoclastismo es el efecto de trituración producto de los cambios de temperatura. Un sólido sometido a un aumento de temperatura se expande, mientras que cuando ésta disminuye, se contrae. Estos ciclos de expansión y contracción tienden a debilitar la estructura de los materiales aun hasta hacer que se trituren, proceso que ocurre más rápidamente cuanto mayores son los cambios de temperatura (Brancucci et al. 2011:52).
Afortunadamente, en la Quebrada de Tarapacá no se presentan las amenazas por contaminación atmosférica y socio-organizativa. En cambio, por la migración de las comunidades aimaras, sí se da la derivada de la disminución demográfica (INE 1995), con la consecuente falta de mantenimiento de los inmuebles. Si bien esto no genera efectos inmediatos, podría producir un daño gradual en los materiales a causa de la presencia de humedad o de erosión por viento, que puede alcanzar $70 \mathrm{~km} / \mathrm{h}$ (DGA 2004), y también por el posible estrés físico generado por la fuerte oscilación térmica, factores que podrían deteriorar los materiales y provocar una mayor vulnerabilidad ante un sismo (Díaz 2015:12).

En el Oasis de Chiu Chiu (Figura 12) también existen indicaciones de un escenario catastrófico por amenaza sísmica, debido a que en aproximadamente 100 años han ocurrido 20 terremotos sobre la magnitud 7, que alcanzó una máxima de 8.3 en 1950 y una intensidad Mercalli de X (CSN 2016). Así de grave es la amenaza de deslizamiento de laderas, ya que la iglesia de Chiu Chiu se emplaza sobre material no consolidado y a menos de 15 metros del cauce del río Loa, el cual aumenta su caudal en el invierno altiplánico y, de hecho, ya ha generado el deslave y la erosión del subsuelo al poniente de la iglesia, pudiendo generar asentamientos diferenciales (Díaz 2016:282).

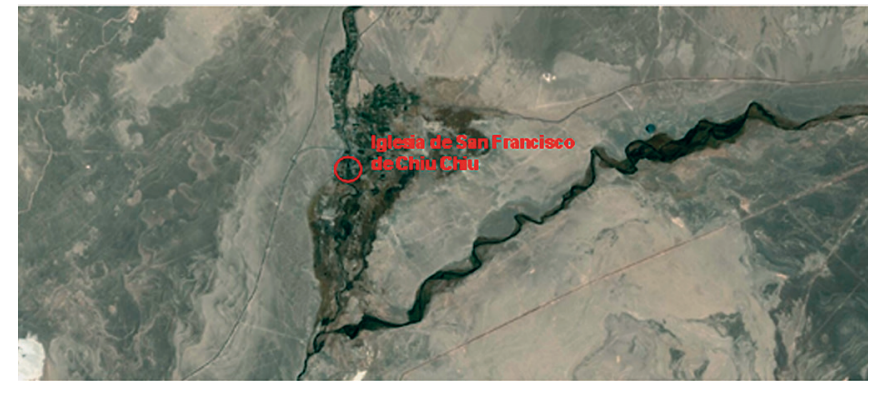

FIGURA 12. Ubicación geográfica de la iglesia en el oasis de Chiu Chiu (Fuente: Google Earth y Geoportal del CMN, Chile, 2015).

Una de las amenazas más sensibles que genera deterioro material de la iglesia de Chiu Chiu es el estrés físico debido a que, prácticamente durante todo el año, se alcanzan temperaturas bajo $0{ }^{\circ} \mathrm{C}$, en coincidencia con la temporada de lluvias (DGA 2016), lo que podría provocar el congelamiento de las partículas de agua y el deterioro gradual del adobe. Por fortuna, las amenazas por contaminación atmosférica, erosión, socio-organizativa o disminución demográfica grave, con la consecuente falta de mantenimiento, no se dan en el Oasis de Chiu Chiu.

Los resultados de la aplicación de la herramienta 2 en los casos de estudio se muestran en la Figura 13.

\section{Aplicación de la herramienta 3}

Debido a que los seis templos corresponden a la tipología arquitectónica de iglesias del altiplano, los elemen- 


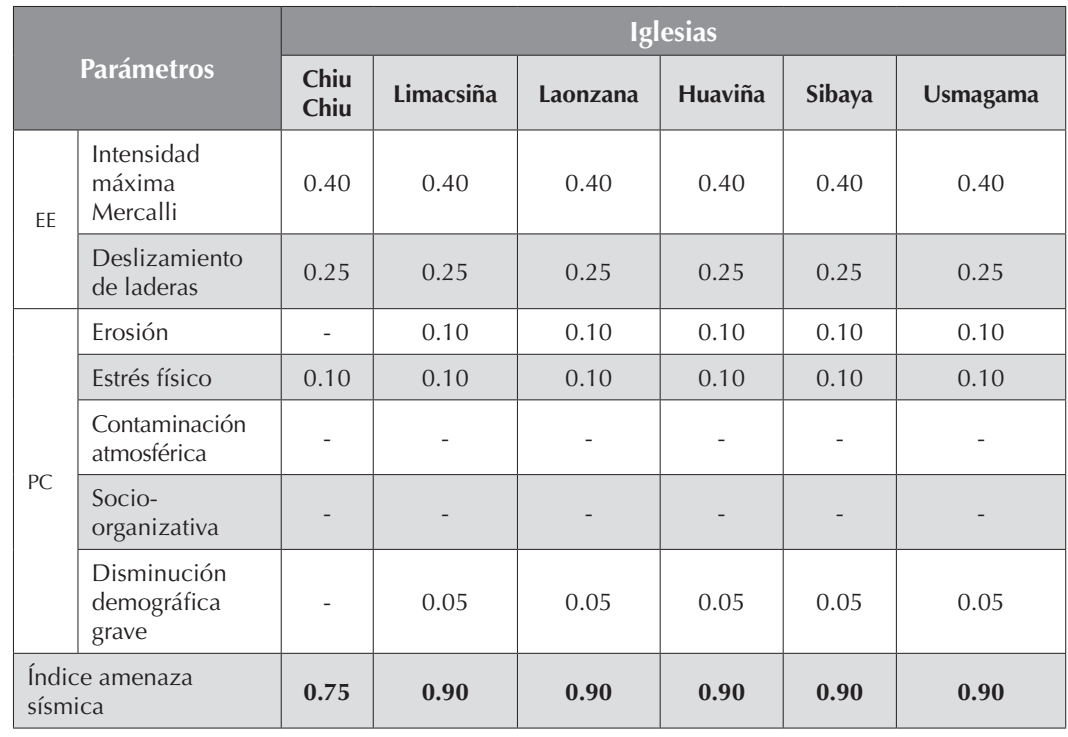

FIGURA 13. Cálculo del índice de amenaza sísmica (Tabla: Daniela Díaz Fuentes, 2016).

tos formales y constructivos que los configuran son: una nave única, capillas adosadas de una altura menor a ésta, una o dos torres en el campanario, cuyo cuerpo superior, en muchos casos, se ha modificado o eliminado, y contrafuertes, que, en general, se han agregado como un refuerzo adicional propio del sistema constructivo tradicional (Jorquera 2014:25). Tanto los muros como los contrafuertes están construidos en adobe o mampostería de piedra asentada en lodo; presentan una estructura de techumbre con sistema de par y nudiIlo de madera, cubierta de paja, lodo o metal. Los resultados de la aplicación de la herramienta 3 en los casos de estudio se muestran en la Figura 14.

\begin{tabular}{|c|c|c|c|c|c|c|c|}
\hline \multirow{2}{*}{\multicolumn{2}{|c|}{ Parámetros }} & \multicolumn{6}{|c|}{ Iglesias } \\
\hline & & \multirow{2}{*}{$\begin{array}{l}\text { Chiu } \\
\text { Chiu }\end{array}$} & \multirow{2}{*}{$\begin{array}{l}\text { Limacsiña } \\
\text { B }\end{array}$} & \multirow{2}{*}{$\begin{array}{l}\text { Laonzana } \\
\text { B }\end{array}$} & \multirow{2}{*}{$\begin{array}{l}\text { Huaviña } \\
\text { B }\end{array}$} & \multirow{2}{*}{$\begin{array}{l}\text { Sibaya } \\
\text { B }\end{array}$} & \multirow{2}{*}{$\begin{array}{l}\text { Usmagama } \\
\text { C }\end{array}$} \\
\hline 1 & $\begin{array}{l}\text { Posición del edificio y } \\
\text { cimentaciones }\end{array}$ & & & & & & \\
\hline 2 & Geometría en planta & $\mathrm{D}$ & $\mathrm{D}$ & $\mathrm{D}$ & $\mathrm{D}$ & $\mathrm{D}$ & D \\
\hline 3 & $\begin{array}{l}\text { Configuración en } \\
\text { elevación }\end{array}$ & A & $\mathrm{A}$ & A & A & A & A \\
\hline 4 & Distancia entre muros & $\mathrm{D}$ & B & $\mathrm{C}$ & C & $\mathrm{C}$ & B \\
\hline 5 & $\begin{array}{l}\text { Elementos no } \\
\text { estructurales }\end{array}$ & A & A & A & A & A & A \\
\hline 6 & $\begin{array}{l}\text { Tipo y organización del } \\
\text { sistema resistente }\end{array}$ & B & $\mathrm{D}$ & $\mathrm{D}$ & $\mathrm{D}$ & $\mathrm{D}$ & D \\
\hline 7 & $\begin{array}{l}\text { Calidad del sistema } \\
\text { resistente }\end{array}$ & B & $\mathrm{D}$ & $\mathrm{D}$ & $\mathrm{D}$ & $\mathrm{D}$ & D \\
\hline 8 & $\begin{array}{l}\text { Estructuras horizontales } \\
\text { (coro) }\end{array}$ & A & A & A & A & A & A \\
\hline 9 & Cubierta & $\mathrm{C}$ & $\mathrm{C}$ & $\mathrm{C}$ & $\mathrm{C}$ & $\mathrm{C}$ & $\mathrm{C}$ \\
\hline 10 & Estado de conservación & $\mathrm{A}$ & $\mathrm{C}$ & $\mathrm{C}$ & C & C & C \\
\hline 11 & Alteraciones del ambiente & B & C & C & C & C & C \\
\hline 12 & $\begin{array}{l}\text { Alteraciones del sistema } \\
\text { constructivo }\end{array}$ & A & B & B & B & $\mathrm{D}$ & $\mathrm{D}$ \\
\hline 13 & Vulnerabilidad al fuego & B & B & B & B & B & B \\
\hline \multicolumn{2}{|c|}{ Índice de vulnerabilidad (V) } & 18.86 & 44.44 & 45.78 & 45.78 & 48.48 & 51.17 \\
\hline
\end{tabular}

FIGURA 14. Cálculo del índice de vulnerabilidad sísmica (Tabla: Daniela Díaz Fuentes, 2016).
Al analizar los resultados del cálculo del índice de vulnerabilidad sísmica, considerando los efectos reales luego del terremoto de junio de 2005 en el norte de Chile, es posible concluir que todas las iglesias que resultaron con una vulnerabilidad sobre 44 de hecho colapsaron con un terremoto de magnitud 7.8 y de intensidad IX-X (Díaz et al. 2012:82-89). Por lo tanto, en un territorio altamente sísmico, como el chileno, sólo superando levemente la vulnerabilidad media esta tipología de iglesias llega al colapso.

En particular, la iglesia de Chiu Chiu resultó con una vulnerabilidad media de 18.86, lo cual concuerda con los datos empíricos, ya que, debido al terremoto mencionado, sufrió daños estructurales reparables y no presentó colapsos. Tal iglesia es un caso ideal para identificar las vulnerabilidades intrínsecas de la tipología "iglesias del altiplano", por contar con un sistema de muros en adobe reflejo de buenas prácticas de construcción tradicional, porque está emplazada en un terreno plano que, además, se encontraba en buen estado de conservación, y no presentaba alteraciones negativas. Tales vulnerabilidades son: la asimetría de la geometría en planta; la excesiva anchura del vano de acceso en relación con el espesor del muro; los vanos de acceso a las capillas en general están muy cerca de las esquinas, lo que debilita la conexión entre muros perpendiculares, y la falta de muros transversales que eviten el volteo de los muros laterales de la nave: debido a ellas, probablemente ninguna iglesia de esta tipología obtendrá un índice de vulnerabilidad inferior a 18.

\section{Conclusiones}

En este trabajo se ha propuesto un nuevo procedimiento, actualmente en vías de perfeccionamiento y aplicación en casos comparativos de estudio en Italia y Chile, para la evaluación del riesgo sísmico del patrimonio cultural, en el marco de una 
investigación de doctorado en la Universidad de la Basilicata (UB, Italia). El enfoque simplificado propuesto se compone de tres herramientas que se aplicaron de manera retroactiva en seis iglesias del norte andino de Chile para determinar si los daños debidos al terremoto de 2005 podrían haberse previsto, e incluso, mitigado, mediante la planificación de la conservación preventiva a escala territorial, ya que este procedimiento permite, por una parte, priorizar la atención de bienes patrimoniales en virtud de un puntaje final de cada uno de ellos y, a la vez, orientar las medidas de mitigación con base en las vulnerabilidades y las amenazas específicas.

La herramienta 1, que prioriza dicha atención dependiendo del valor patrimonial, es la más limitada en su ámbito de aplicación debido a que se creó para el patrimonio inmueble histórico, pero no para el arqueológico, con el objeto de utilizar los instrumentos de gestión del patrimonio vigentes en los gobiernos latinoamericanos, como los decretos de declaratoria y las fichas de catálogo. Lo anterior se debe a que estos documentos reflejan un consenso en el ámbito del Estado, que responde a una definición específica de patrimonio cultural y a la legislación en materia de su tutela en cada país. Ante la recurrencia de las catástrofes derivadas de fenómenos naturales es necesario contar con una herramienta que permita evaluar el valor cultural a escala territorial ponderando los bienes culturales inmuebles con base en criterios comunes, con la finalidad de priorizar la atención y el financiamiento de proyectos ante un escenario de catástrofe y recursos escasos. Si bien tal herramienta no tiene en consideración la mutabilidad de los juicios de valor en el tiempo, su inclusión en una plataforma dinámica de manejo de la información, como los sistemas de información geográfica (SIG), permitiría su constante actualización.

Respecto de la aplicación de la herramienta 1 en los casos de estudio, si bien la ponderación es similar por razón de que las seis iglesias corresponden a la misma tipología histórico-arquitectónica, las principales diferencias se obtuvieron en el valor estético, según el grado de alteración de los templos, que lo ha mermado al dificultar la legibilidad de la tipología. Por otra parte, los valores que marcaron la diferencia entre la iglesia que obtuvo el mayor puntaje: San Francisco de Chiu Chiu, y el resto de los casos de estudio, fueron los valores de antigüedad y de uso.

En relación con la herramienta 2, no obstante que la diferencia cuantitativa entre los dos contextos territoriales no es determinante, debido a que en ambos casos se presentaban amenazas que podrían generar escenarios catastróficos por la intensidad sísmica y deslizamientos de laderas, la ventaja del análisis cualitativo de cada una de ellas es que permite orientar las medidas de mitigación.

En cuanto a la herramienta 3, la cuantificación final permitió, además de identificar los inmuebles más vulnerables entre casos de estudio, definir las principales vul- nerabilidades de esta tipología de iglesias, así como las específicas de cada caso, lo que también orientó las medidas de conservación preventiva. Por ejemplo, la iglesia con mayor puntaje presentó un emplazamiento en pendiente, alteraciones en el sistema constructivo con materiales incompatibles y conexiones ineficientes entre los muros de mampostería, así como entre los muros y la cubierta.

Finalmente, la evaluación del riesgo sísmico resulta de la multiplicación de los índices resultantes de las herramientas 2 y 3, como se observa en la Figura 15.

En virtud de la evaluación del riesgo sísmico en los casos de estudio, es posible determinar la aplicabilidad de este procedimiento en América Latina, primero, por su efectividad en términos numéricos, ya que todas las iglesias con una vulnerabilidad sísmica superior a 44 colapsaron con un terremoto de magnitud 7.8 e intensidad IX-X. Este puntaje, multiplicado por un índice de amenaza alto, como en los casos de estudio (0.9), da como resultado un riesgo sísmico máximo cercano a 100. En el caso de la iglesia de Chiu Chiu, su riesgo sísmico total, de 33, también es coherente, ya que a causa del terremoto resultó con daños reparables. No obstante, en términos de valor cultural se debería haber priorizado la intervención en la iglesia menos vulnerable, cuyas medidas de conservación preventiva habrían disminuido los plazos de recuperación posterremoto y la pronta restitución de su uso por parte de la comunidad atacameña.

Con las herramientas 2 y 3 se determinan, en cierta medida, los planes de conservación del inmueble y su entorno; por ejemplo, algunas obras de mitigación de amenazas resultado del análisis son: la realización de estudios de mecánica de suelos en todos los casos; la regularización de los sistemas de drenaje en las construcciones en la ladera de la quebrada y la ejecución de muros de contención, y los estudios para el encauzamiento del río Loa y la consolidación del suelo en torno a la iglesia de Chiu Chiu. En esta iglesia, las obras de mitigación, la ejecución de una estructura horizontal continua de coronamiento de los muros para transmitir homogéneamente las cargas de la cubierta y un mantenimiento regular habrían disminuido su vulnerabilidad sísmica.

Por otra parte, para disminuir la vulnerabilidad de las iglesias de la Quebrada de Tarapacá, algunas medidas de conservación preventiva necesarias son: el refuerzo de las esquinas —debilitadas por la presencia de vanos cercanos-, por ejemplo, mediante la incorporación de escalerillas de madera entre las hiladas para mejorar el comportamiento monolítico del edificio; el reforzamiento de los muros longitudinales de la nave mediante su consolidación con geomallas y mejorando las conexiones con los contrafuertes; la incorporación de una estructura horizontal continua de coronamiento de los muros capaz de transmitir homogéneamente las cargas de la cubierta; el rejunteo con mortero de lodo mejorado con cal; el remamposteo de piedras o de los adobes deteriorados; el 


\begin{tabular}{|l|c|c|c|c|c|c|}
\hline \multirow{2}{*}{\multicolumn{1}{|c|}{ Parámetros }} & \multicolumn{5}{c|}{ Iglesias } \\
\cline { 2 - 7 } & Chiu Chiu & Limacsiña & Laonzana & Huaviña & Sibaya & Usmagama \\
\hline Índice de vulnerabilidad $(\mathrm{V})$ & 18.86 & 44.44 & 45.78 & 45.78 & 48.48 & 51.17 \\
\hline Índice de amenaza $(\mathrm{A})$ & 0.75 & 0.90 & 0.90 & 0.90 & 0.90 & 0.90 \\
\hline Índice de riesgo sísmico $\mathrm{R}=\mathrm{V}^{*}(\mathrm{~A}+1)$ & $\mathbf{3 3 . 0 0}$ & $\mathbf{8 4 . 4 3}$ & $\mathbf{8 6 . 9 9}$ & $\mathbf{8 6 . 9 9}$ & $\mathbf{9 2 . 1 0}$ & $\mathbf{9 7 . 2 1}$ \\
\hline
\end{tabular}

FIGURA 15. Cálculo del índice de riesgo sísmico (Tabla: Daniela Díaz Fuentes, 2016).

aplanado de los muros de la iglesia con morteros mejorados con cal, y la seguridad de que se llevarán a cabo constantemente el mantenimiento y el monitoreo.

Finalmente, es posible concluir que la metodología propuesta permite definir una prioridad numérica e identificar las principales vulnerabilidades y amenazas para orientar estudios específicos que, en el marco de esta investigación, constituyen el planteamiento inicial de un plan de conservación, para después llevar a cabo la propuesta integral de conservación o preservación de los bienes culturales inmuebles.

\section{Agradecimientos}

Los apoyos económicos para el desarrollo de esta investigación fueron concedidos por Erasmus Mundus-Action 2, Partnerships Programme [EMA2] mediante el proyecto de beca y movilidad "Euro-Latin America Partnership in Natural Risk Mitigation and Protection of the Cultural Heritage-ELARCH" (ELARCH 2016), financiado por la Comisión Europea y coordinado por la Universidad de la Basilicata (UB), Italia. Este documento refleja sólo la opinión del autor, y la Comisión no se hace responsable por cualquier uso que pueda hacerse de la información de su contenido.

\section{Referencias}

Angelis, Guglielmo De

1972 Guida allo studio metodico dei monumenti e delle loro cause di deterioramento, Juana Gómez Badillo (trad.), Roma, México, ICCROM/Universidad de Roma, ENCRyM.

\section{Ballart, Josep}

1997 El patrimonio histórico y arqueológico: valor y uso, Barcelona, Ariel.

Binda, Luigia y Antonella Saisi

2001 "State of the Art of Research on Historic Structures in Italy", Advanced Research Centre for Cultural Heritage Interdisciplinary Projects, documento electrónico disponible en [http://www.arcchip.cz/w11/w11_binda.pdf], consultado en mayo de 2015.

Brancucci, Gerardo, Valentina Marin y Paola Salmona 2011 Geomorfologia applicata. Appunti alle lezioni per studenti di architettura, Padua, libreriauniversitaria.it edizioni [página web].

Carocci, Caterina

2001 "Guidelines for the safety and preservation of histori- cal Centres in Seismic Areas", Historical Constructions, documento electrónico disponible en [http://www.hms.civil.uminho.pt], consultado en mayo de 2015.

CDT

2012 Evaluación de daños y soluciones para construcciones en tierra cruda. Manual de terreno, Santiago, Raizfutura/CDT (Corporación de Desarrollo Tecnológico).

CDCMN

2009a Expediente del Monumento Histórico Capilla de Laonzana, documento inédito mecanoescrito, Chile, CDCMN (Centro de Documentación del Consejo de Monumentos Nacionales).

2009b Expediente del Monumento Histórico Iglesia de San Salvador de Limaxiña, documento inédito mecanoescrito, Chile, CDCMN (Centro de Documentación del Consejo de Monumentos Nacionales).

2009c Expediente del Monumento Histórico Iglesia de Sibaya, Chile, CDCMN (Centro de Documentación del Consejo de Monumentos Nacionales).

1953a Expediente del Monumento Histórico Iglesia de Usmagama, Chile, CDCMN (Centro de Documentación del Consejo de Monumentos Nacionales).

1953b Expediente del Monumento Histórico Iglesia de Huaviña, Chile, CDCMN (Centro de Documentación del Consejo de Monumentos Nacionales).

1951 Expediente del Monumento Histórico Iglesia de San Francisco de Chiu Chiu, Chile, CDCMN (Centro de Documentación del Consejo de Monumentos Nacionales).

Cenapred

2001 Diagnóstico de peligros e identificación de riesgos de desastres en México, México, Secretaría de Gobernación/Cenapred (Centro Nacional de Prevención de Desastres).

2006 Guía básica para la elaboración de atlas estatales y municipales de peligros y riesgos. Conceptos básicos sobre peligros, riesgos y su representación geográfica, México, Secretaría de Gobernación/Cenapred (Centro Nacional de Prevención de Desastres).

Choay, Françoise

2007 Alegoría del patrimonio, María Betrand Suazo (trad.), Barcelona, Gustavo Gili.

CMN

2004 Lista tentativa de bienes culturales de Chile a ser postulados como sitios del patrimonio mundial, Santiago, CMN (Consejo de Monumentos Nacionales), Serie Cuadernos del Consejo de Monumentos Nacionales, Segunda Serie, núm. 30. 
CSN

2016 Sismos importantes y/o destructivos (1570 a la fecha). Magnitud Ms mayor o igual a 7.0, Centro Sismológico Nacional de la Universidad de Chile, documento electrónico disponible en [http://www.sismologia.cl/seismo.html], consultado en noviembre de 2016.

D'Ayala, Dina y Elena Speranza

2002 "An integrated procedure for the assessment of seismic vulnerability of historic buildings", en $12^{\text {th }}$ European Conference on Earthquake Engineering, Londres, Elsevier Science, $1-10$.

De la Torre, M. (ed.)

2002 Assessing the Values of Cultural Heritage, Los Ángeles, The Getty Conservation Institute (GCI).

Degg, Martin y Dave Chester

2005 "Seismic and volcanic hazards in Peru: Changing attitudes to disaster mitigation", The Geographical Journal 171, (2):125-145.

DGA

2004 Diagnóstico y clasificación de los cursos y cuerpos de agua según objetivos de calidad, Cuenca Quebrada de Tarapacá, DGA (Dirección General de Aguas), Ministerio de Obras Públicas de Chile, documento electrónico disponible en [http://www.sinia.cl/1292/articles-31018_Tarapaca.pdf], consultado en noviembre de 2016.

2016 Información oficial hidrometeorológica y de calidad de aguas en línea, DGA (Dirección General de Aguas), Ministerio de Obras Públicas de Chile, documento electrónico disponible en [http://snia.dga.cl/BNAConsultas/reportes], consultado en noviembre de 2016.

DGPTA

2003 Rilevamento della vulnerabilità sismica degli edifici in muratura. Manuale per la compilazione della Scheda GNDT/ CNR di Il livello, Roma, Direzione Generale delle Politiche Territoriale e Ambientali (DGPTA), documento electrónico disponible en [http://www.regione.toscana.it/documents], consultado en noviembre de 2016.

Díaz, César

2008 "Lesiones estructurales en los edificios de la arquitectura tradicional mediterránea", en J. Casanovas (dir.), Método Rehabimed, arquitectura tradicional mediterránea, II, Barcelona, Consorcio Rehabimed, 195-208.

Díaz, Daniela, María Eugenia Espiñeira, Gloria Núnez y Christian Matzner (eds.)

2012 I Reunión Técnica Iglesias del Altiplano: Intervenciones Arquitectónicas y Arqueológicas en los Monumentos Nacionales. Lineamientos de Intervención para Proyectos Bicomponente: Arquitectura y Arqueología, Santiago, CMN (Consejo de Monumentos Nacionales), Cuadernos del Consejo de Monumentos Nacionales, Segunda Serie, 110.

Díaz Fuentes, Daniela

2015 “Evaluación del riesgo del patrimonio religioso de la Quebrada de Tarapacá: el abandono y la pérdida de la tradición constructiva como detonantes de su vulnerabilidad ante la amenaza sísmica", tesis en cultura, Santiago, documento electrónico disponible en [http://www.observatoriocultural. gob.cl/haz-tu-tesis-en-cultura/466], consultado en noviembre de 2016.

2016 Diseño de herramientas de evaluación del riesgo para la conservación del patrimonio cultural inmueble. Aplicación en dos casos de estudio del norte andino chileno, México, Publicaciones ENCRYM/INAH.

Dibam

2016a Iglesia de Huaviña, Dibam (Dirección de Bibliotecas, Archivos y Museos de Chile), documento electrónico disponible en [http://www.monumentos.cl/catalogo/625/w3-article-26101.html], consultado en noviembre de 2016.

2016b Iglesia de Usmagama, Dibam (Dirección de Bibliotecas, Archivos y Museos de Chile), documento electrónico disponible en [http://www.monumentos.cl/catalogo/625/w3article-26102.html], consultado en noviembre de 2016.

2016c Nómina de monumentos nacionales desde 1925 al 5 de septiembre del 2016, Dibam (Dirección de Bibliotecas, Archivos y Museos de Chile), documento electrónico disponible en [http://www.monumentos.cl/consejo/606/w3-article-53680.html], consultado en noviembre de 2016.

ELARCH

2016 Euro-Latin American Partnership in Natural Risk Mitigation and Protection of the Cultural Heritage, documento electrónico disponible en [www.elarch.org], consultado en noviembre de 2016.

Feilden, Bernard

1987 Between Two Earthquakes: Cultural Property in Seismic Zones, Roma, ICCROM y GCI.

Guida, Antonella, Michelangelo Laterza, Antonello Pagliuca, Michele D'Amato, Daniela Díaz y Marcella Chietera

2016 "Technological characterization for the mitigation of seismic risk. The case study of churches in Sassi di Matera", ponencia presentada en la conferencia Ar.Tec Colloqui.AT.e, 12-15 de octubre, Italia, Università degli Studi della Basilicata.

ICCROM Y UNESCO

2009 Manual de gestión de riesgos de colecciones, documento electrónico disponible en [http://unesdoc.unesco.org/ images/0018/001862/186240s.pdf], consultado en mayo de 2015.

ICOMOS

1994 Documento de Nara, Japón, Sobre la autenticidad de los valores patrimoniales, documento electrónico disponible en [http://www.icomoscr.org], consultado en abril de 2015.

2013 The Burra Charter: The Australia ICOMOS Charter for the Conservation of Places of Cultural Significance, Sidney, Australia, ICOMOS.

ICR

1992 Carta del Rischio, ICR (Istituto Superiore per la Conservazione), documento electrónico disponible en [http://www. cartadelrischio.it/index.asp], consultado en noviembre de 2016.

INAH

2002, 2009 y 2013 Programa de prevención de Desastres en Materia de Patrimonio Cultural, México, INAH (Instituto Nacional de Antropología e Historia). 
2010 Lineamientos para la elaboración de dictámenes de siniestros en caso de desastre PreviNAH. Manual para conservadores, México, Coordinación Nacional de Monumentos Históricos (CMNH-INAH).

INE

1995 Chile: Ciudades, pueblos y aldeas. Censo de 1992, INE (Instituto Nacional de Estadísticas), documento electrónico disponible en [www.ine.cl], consultado en abril de 2015.

INN

2013 Norma chilena núm. 3332, oficializada el año 2013: Estructuras-intervención de construcciones patrimoniales de tierra cruda. Requisitos del proyecto estructural, Santiago, INN (Instituto Nacional de Normalización).

Jorquera, Natalia

2012 "Culturas constructivas en tierra y riesgo sísmico. El caso de la arquitectura tradicional chilena y la evaluación de su vulnerabilidad frente a la acción sísmica", en XI Conferencia Internacional sobre el Estudio y Conservación del Patrimonio Arquitectónico de Tierra: Terra 2012, Lima.

2014 "Culturas sísmicas: estrategias vernaculares de sismorresistencia del patrimonio arquitectónico chileno", Arquitecturas del Sur, 46 (XXXII):18-29.

Laterza, Michelangelo, Antonella Guida, Michele D'Amato, Antonello Pagliuca, Daniela Díaz y Marcella Chietera

2016a "Technical and technological qualification of ancient buildings. The case of churches in 'Sassi di Matera'", ponencia presentada en la XII International Conference on Structural Repair and Rehabilitation, 26-29 de octubre, Portugal, Faculdade de Engenharia da Universidade do Porto.

Laterza, Michelangelo, Michele D'Amato y Daniela Díaz

2016b "Ancient masonary cathedrals in Matera landscape: seismic assessment and risk mitigation", ponencia presentada en la XII International Conference on Structural Repair and Rehabilitation, 26-29 de octubre, Portugal, Faculdade de Engenharia da Universidade do Porto.

MC

2005 Manual para inventarios. Bienes culturales inmuebles, Bogotá, MC (Ministerio de Cultura, Dirección de Patrimonio). ME

2009 Decreto con toma de razón núm. 0013, Santiago 27/01/2009, ME (Ministerio de Educación, Gobierno de Chile).

2016 Ley 17.288 de Monumentos Nacionales y Normas Relacionadas, 6.a ed., Santiago, ME (Ministerio de Educación, Consejo de Monumentos Nacionales).

Modena, Claudio et al.

2009 "Structural Interventions on Historical Masonry Buildings: Review of Eurocode 8. Provisions in the light of the Italian experience", en E. Cosenza (ed.), Eurocode 8 Perspectives from the Italian Standpoint Workshop, Nápoles, Doppiavoce 225-236.
OGPMV - ENEA

2008 Manejo de riesgos en Valparaíso, servicios técnicos. Peligro de incendio en la ciudad de Valparaíso, proyecto desarrollado por ENEA (Agenzia nazionale per le nuove tecnologie, I'energia e lo sviluppo economico sostenibile), Italia, y OGPMV (Oficina de Gestión Patrimonial de la Municipalidad de Valparaíso), Chile, y financiado por el Banco Interamericano de Desarrollo (BID), documento electrónico disponible en [http://www.marvasto.bologna.enea.it.]

Riegl, Aloïs

1903 El culto moderno a los monumentos. Caracteres y origen, Ana Pérez López (trad.), Viena y Leipzig, Madrid, Visor.

Roca, Pere

2008 "El comportamiento sísmico de las construcciones tradicionales de paredes de obra de fábrica", en J. Casanovas (dir.), Método Rehabimed. Arquitectura tradicional mediterránea, vol. II, Barcelona, Consorcio Rehabimed, 216-225.

Sernageomin

2003 Mapa geológico de Chile: versión digital, publicación geológica digital núm. 4 (CD-ROM, versión1.0, 2003), Santiago, Sernageomin (Servicio Nacional de Geología y Minería).

Stovel, Herb

1998 Risk Preparedness: A Management Manual for World Cultural Heritage, Roma, ICCROM/UNESCO/WHC/ICOMOS.

Subdere

2011 Guía de análisis de riesgos naturales para el ordenamiento territorial, Santiago, Subdere (Subsecretaría de Desarrollo Regional y Administrativo).

UNESCO

2008 Directrices prácticas para la aplicación de la Convención del Patrimonio Mundial, documento electrónico disponible en [http://whc.unesco.org/archive/opguide08-es.pdf], consultado en noviembre de 2016.

2010 Managing Disaster risks for World Heritage (Gestión del riesgo de desastres para el Patrimonio Mundial), París, UNESCO/ICCROM/ICOMOS/IUCN, documento electrónico disponible en [http://whc.unesco.org/en/managing-disaster-risks/], consultado en diciembre de 2016.

UNISDR

2009 Terminology on disaster risk reduction, Geneva, United Nations Office for Disaster Risk Reduction (UNISDR). USGS

2016 "Ring of Fire", Earthwake Glossary, Washington, United States Geographical Survey (USGS), documento electrónico disponible en [https://earthquake.usgs.gov/learn/ glossary/?term=Ring\%20of\%20Fire], concultado en noviembre de 2016.

Wikiwand

San Francisco de Chiu Chiu, documento electrónico disponible en [http://www.wikiwand.com/es/San_Francisco_de_ Chiu_Chiu], consultado en noviembre de 2016. 


\section{Síntesis curricular del/los autor/es}

\section{Daniela Andrea Díaz Fuentes}

Università degli Studi della Basilicata (UNIBAS), Italia

daniela.diazfue@gmail.com

Arquitecta (Universidad de Chile, $\mathrm{UCH}$, Chile) y maestra en conservación y restauración de bienes culturales inmuebles (Escuela Nacional de Conservación, Restauración y Museologia, Instituto Nacional de Antropología e Historia [ENCRyM-INAH], MéxiCo). Actualmente se encuentra cursando estudios de doctorado (Dipartimento delle Culture Europee e del Mediterraneo (DICEM, Departamento de Culturas del Mediterráneo), Università degli Studi della Basilicata [UNIBAS], Universidad de la Basilicata) Matera, Italia). En 2016 fue galardonada por el Premio INAH, México, a la mejor tesis de maestria en conservación-restauración de monumentos.

Postulado/Submited 12.04.2016

Aceptado/Acepted 22.12.2016

Publicado/Published 31.01.2017 